\title{
Application of Repeated Measures Method to Compare Physical Maternal Health Index in a Follow-up Study
}

\author{
Hourieh Shamshiri Milani ${ }^{1,2}$, Nezhat Shakeri ${ }^{3} \&$ Taha Asbaghi $^{2}$ \\ ${ }^{1}$ Infertility and Reproductive Health Research Centre (IRHRC), Shahid Beheshti University of Medical Sciences, \\ Tehran, Iran \\ ${ }^{2}$ Health and Community Medicine Department, Faculty of Medicine, Shahid Beheshti University of Medical \\ Sciences, Tehran, Iran \\ ${ }^{3}$ Department of Biostatistics, Faculty of Paramedical Sciences, Shahid Beheshti University of Medical Sciences, \\ Tehran, Iran \\ Correspondence: Nezhat Shakeri, Department of Biostatistics, Faculty of Paramedical Sciences, Shahid Beheshti \\ University of Medical Sciences, Tehran, Iran. E-mail: n.shakeri@sbmu.ac.ir
}

Received: March 2, 2016 Accepted: June 16, 2016 Online Published: July 29, 2016

doi:10.5539/gjhs.v9n3p276 URL: http://dx.doi.org/10.5539/gjhs.v9n3p276

\begin{abstract}
Maternal health is a concept indicating the health of mothers during pregnancy, childbirth and the post-partum period. Recent literature indicates that the maternal mortality rate in Iran is 23 per 100,000 live birth. For every death, 20 to 30 mothers suffer from chronic and acute illnesses arising from pregnancy and delivery; therefore, using a valid and reliable indicator will help researchers assess maternal health more precisely. In this longitudinal study, attempt has been made to compare mothers' health status by using a subjective tool for evaluating the Physical-Maternal Health Index (P-MHI). The most common complaints made by mothers were headache, back pain, mastitis, nipple fissure, breast abscess, abdominal pain, pain in genitalia, constipation, hemorrhoids, anal fissure, urinary problems/Incontinence, fatigue, and dizziness/vertigo. The P-MHI is defined on the basis of these complaints scaling $0-100$. The higher the index, the better the health status of mothers. It was administered by structured interviews with 743 participants before and during pregnancy, one week, two, four, and six months after childbirth (2010-2011). Post-natal mothers experience various problems, with back pain and fatigue being the most common. The P-MHI was at its lowest level in the first week after delivery (76 out of 100), followed by the second month ( 82 out of 100). The results showed that not only do mothers significantly lose their reproductive health after pregnancy, they don't attain their pre-pregnancy health status even six months after delivery $(\mathrm{P}<0.0005)$. The trend of the P-MHI identified when and what kind of health care is the most urgent need of post-natal mothers.
\end{abstract}

Keywords: Iran, longitudinal study, Physical-Maternal Health Index, pregnancy, women's health

\section{Introduction}

Maternal health is a concept indicating the health of mothers during pregnancy, childbirth and the post-partum period. According to Catalin and Irina (2006), for centuries childbirth was considered only a physiological phenomenon. Today, however, it has another meaning for people who are concerned about maternal health in the short- and long-term. Some mothers suffer from several health-related problems during and after childbirth, due to their maternal duties and the additional responsibilities after arrival of the newborn baby in the family. Experience shows that mothers value their children's health six times greater than their own health (Nastis \& Crocker, 2012).

Indices relating to the health of mothers are considered to be among the most important development indices of every country. In the past the assessment of mothers' health was established with the aid of the Maternal Mortality Rate (MMR), which is based on the proportion of mother's deaths with respect to the number of live births in a specified period. According to the World Health Organization's (WHO) Millennium Development Goals (MDGs), MMR has dramatically declined over the past decades in Iran: of 83 per 100,000 live births in the year 1990, the ratio dropped to 23 per 100,000 live births in 2013 (World Health Organization, 2013-2014). In view of the fact that for every death, 20 to 30 mothers suffer from chronic and acute illnesses arising from pregnancy and delivery (Ashford, 2002; Reichenheim, Zylbersztajn, Moraes, \& Lobato, 2009), simply relying on the number of deaths 
cannot be a sufficient indicator of assessing mothers' health. More precise indicators related to the illnesses are necessary. "Near Misses" term was introduced for assessing the cases of severe maternal mortality. Jayaratnam S, et al. (2011) collected near-miss data and concluded that it is a useful instrument but is a prolonged process and medical personnel should have persistent attention. (Jayaratnam, De Costa, \& Howat, 2011). Callaghan WM et al. (2012) aimed to offer a new scale for severe maternal morbidity during childbirth and postpartum. They found that assessing the cases could help distinguish the best time for intervention (Callaghan, Creanga, \& Kuklina, 2012).

Various studies have addressed the difficulties and complaints of mothers in the post-partum period, such as studies which have referred to low back pain (LBP), fatigue, and headache (Olsson, Nilsson-Wikmar, \& Grooten, 2012; Mens, Huis In 't Veld, \& Pool-Goudzwaard 2012; Goldszmidt, Kern, Chaput, \& Macarthur, 2005; Klein \& Loder, 2010; Vermani et al., 2010). Glazener stated that maternal morbidity is prevalent, noting that $76 \%$ of mothers reported at least one health problem after eight weeks of pregnancy. He suggested measures that would decrease maternal health problems as an important issue (Glazener, 1995). Some researchers, however, have tried to study the well-being of mothers and have introduced instruments to measure mothers' health and quality of life. Symon A, et al. introduced the mother-generated index, and assessed the post-natal quality of life (Symon, MacDonald, Ruta, 2002). Symon reviewed mothers' prenatal and post-natal quality of life and concluded that few devices have been designed to be used in the settings of maternal care (Symon, 2003). He suggested making a device through which mothers could specify the most important aspects of their quality of life (Symon, MacKay, \& Ruta, 2003).

Jones and his colleagues suggested two instruments for measuring positive and negative effects of parenting on mothers' and fathers' health. They studied several aspects of quality of life, but their participants complained of several physical problems, e.g. urinary incontinence, pain, etc. (Jones et al., 2011). There were a few questionnaires that specifically assessed mothers' complications. For example, Lacasse and Berard (2008) validated a questionnaire on nausea and vomiting during pregnancy, but there was no adequate measurement for assessing mothers' physical health from a common medical complications point of view.

To improve the post-natal health of mothers, in addition to the overall families' health, a reliable overview of the situation will help improve maternal programs accurately.

A fundamental question regarding a mother's health is: During what period is the mother's physical health at its lowest level? In the course of time, will mothers be able to return to their original health? In order to answer these questions it is necessary to use the standard questionnaire for the assessment of physical health.

Considering the fact that there is currently no standard tool for evaluating maternal health (Firoz et al., 2013), a standard questionnaire for the precise assessment of mothers' physical health was devised. With the aid of this questionnaire, Physical Maternal Health Index (P-MHI) was established. This indicator establishes the level of health without taking into consideration the kind of reported discomfort a mother has. With the help of this indicator, assessments were made for six time periods: before pregnancy; during pregnancy; one week after delivery; two, four, and six months after delivery, and comparisons were made. This comparison can show in what periods of time mothers' health is at a higher risk, and show the mothers' health six months after delivery as compared to the time before pregnancy.

By using the findings of this study, policy makers will be able to execute an adequate maternal health-related program.

\section{Method}

\subsection{Participants' Characteristics}

Initially, mothers who had two-month-old babies and had sought child health care services from health centers in Tehran were recruited. Mothers who had history of severe injuries or diseases did not included in the study.

\subsection{Sampling Procedure}

\subsubsection{Research Design}

In a longitudinal study, 15 health centers were randomly selected as clusters. From each center a midwife from The Mother and Child Unit was selected as a research assistant. These assistants were trained in a workshop on how to question and how to follow up the mothers' responses. After collecting data a gynecologist randomly selected some of the questionnaires and checked the responses by asking the questions from mothers by phone. A written consent was obtained from mothers. According to the current scheme of children's health care in Iran, WHO proposed a regular vaccination program to be compulsory for two-, four- and six month-old babies and free of charge all across the country. These services are provided by Health Care Centers. Therefore, mothers generally 
visited the center two, four and six months after delivery. Therefore, the first time that the mothers were accessible was two months after delivery, and their previous complaints could be asked at this time. Using the questionnaire, at the outset mothers were asked about thirteen medical complications of the second month after delivery (the time of interview) and three previous time points, i.e., before pregnancy, during pregnancy, and one week after delivery. Meaning that due to inaccessibility to the mothers before and immediately after childbirth, the questionnaires relating to the second month and three previous time points were collected at the second month simultaneously.

The interviews were repeated, at the fourth and sixth month after delivery. If mothers didn't refer to the health center within the stipulated time, they were contacted by phone. And if they failed to respond after being called twice, they were excluded from the study. All the statements were signed by the mothers, and they were assured of the confidentiality of the information.

\subsubsection{Measures and Covariates}

A questionnaire that included personal information and reproductive health-related queries was administered. Face and content validity were solicited through consultations with gynecologists. A pilot study was conducted to assess the reliability of the questionnaire and its internal consistency was examined by the test-retest method. The P-MHI questionnaire was finalized, including the following items:1-Headache (0-Yes, 1-No); 2- Back pain (0-Yes, 1-No); 3-Mastitis (0-Yes, 1-No); 4-Nipple Fissure (0-Yes, 1-No); 5-Breast Abscess (0-Yes, 1-No); 6-Abdominal Pain (0-Yes, 1-No); 7- Pain in Genitalia (0-Yes, 1-No); 8-Constipation (0-Yes, 1-No); 9-Hemorrhoids (0-Yes, 1-No); 10-Anal Fissure (0-Yes, 1-No); 11-Urinary problems/Incontinence (0-Yes, 1-No); 12-Fatigue (0-Yes, 1-No); 13Dizziness/Vertigo (0-Yes, 1-No).

For calculating P-MHI, while asking about 13 complications, if for example a mother complained from headache she will get 0 score and if she doesn't have headache problem she will get 1 score. Adding these 13 scores will provide total score which shows the level of mother's health. Total score would be a number between 0 to 13 . For making comparisons easier, the scale of total score will be changed to 100 , by calculating $100 *$ total score/ 13 . This number would be considered as P-MHI. The lower the index, the lower the health status of the mother.

\subsubsection{Sample Size Determination}

By considering $\alpha=0.05, \beta=0.2, \sigma=5$ and $\mu 1-\mu 2=0.9$ and $20 \%$ effect size and $10 \%$ attrition rate, a sample size of 740 was obtained.

Since the participants were followed up longitudinally at six different points in time, and since P-MHI is a numerical variable, repeated measures analysis of variance method were employed to compare the means of the index at different time stages. In order to test the difference of the proportion of the complaints, the Cochran test was employed. All statistical analyses were done by SPSS 16.

\section{Results}

\subsection{Recruitment}

A total number of 743 mothers were recruited for the study during 2010-2011.

\subsection{Baseline Data}

The age range was 14 to 43 years. Mean (SD) of their ages was $28 \pm 5$ years, with half of them between 25 to 31 years. Seventy-six percent were high school graduates or above; $52 \%$ of the mothers were pregnant for the first time, and $31 \%$ for the second time; $40 \%$ of the deliveries were done by Cesarean section (Cs).

\subsection{Statistics and Data Analysis}

Table 1 shows the complaints of mothers before pregnancy as baseline information, and during the different stages of follow-up. Table 1 indicates that before pregnancy mothers had reported back pain $(20 \%)$, headache (15\%), constipation (15\%), fatigue (8\%), hemorrhoids (7\%), dizziness/vertigo (6\%), fissure (6\%), and other problems like mastitis, abdominal pain, pain in the genitalia and urinary problems/incontinence, less that $2 \%$ for each. We are witness to an increase in the percentages of reported discomforts during pregnancy, for example, back pain increased to $50-52 \%$ during pregnancy and a week after childbirth. Investigations showed that when collecting the data the same participants who had an specific problem during their pregnancy the same participants had it postpartum.

Headache reached $30 \%$ one week after delivery. Back pain remained the same even after two months. The Cochran test revealed the increasing trend of complaints from pre-pregnancy to the first week after delivery. It shows that the mothers experienced health-related problems during the first week after childbirth more than at other times $(\mathrm{P}<0.0005)$. The most prevalent post-natal complaints of mother were headache, back pain, nipple fissure, 
abdominal pain, constipation, fatigue and dizziness.

Table 1. Complaints of mothers at six different points in time

\begin{tabular}{|c|c|c|c|c|c|c|c|}
\hline \multirow[b]{2}{*}{ No } & \multirow[b]{2}{*}{ Mother's Complaint } & \multirow[b]{2}{*}{$\begin{array}{l}\text { Before } \\
\text { Pregnancy } \\
(\%)\end{array}$} & \multirow[b]{2}{*}{$\begin{array}{l}\text { During } \\
\text { Pregnancy } \\
(\%)\end{array}$} & \multicolumn{4}{|c|}{ After delivery } \\
\hline & & & & $\begin{array}{l}\text { One } \\
\text { week } \\
(\%)\end{array}$ & $\begin{array}{l}\text { Two } \\
\text { months } \\
(\%)\end{array}$ & $\begin{array}{l}\text { Four } \\
\text { months } \\
(\%)\end{array}$ & $\begin{array}{l}\text { Six } \\
\text { months } \\
(\%)\end{array}$ \\
\hline 1 & Headache & 15 & 24 & 30 & 26 & 21 & 22 \\
\hline 2 & Back pain & 20 & 50 & 52 & 52 & 45 & 39 \\
\hline 3 & Mastitis & 1 & 2 & 15 & 4 & 3 & 2 \\
\hline 4 & Nipple Fissure & 0 & 1 & 31 & 7 & 2 & 2 \\
\hline 5 & Breast Abscess & 0 & 0 & 3 & 1 & 1 & 1 \\
\hline 6 & Abdominal Pain & 2 & 13 & 29 & 10 & 10 & 8 \\
\hline 7 & Pain in Genitalia & 2 & 15 & 23 & 11 & 11 & 8 \\
\hline 8 & Constipation & 15 & 19 & 35 & 30 & 18 & 14 \\
\hline 9 & Hemorrhoids & 7 & 10 & 12 & 14 & 11 & 8 \\
\hline 10 & Anal Fissure & 6 & 6 & 12 & 17 & 12 & 10 \\
\hline 11 & $\begin{array}{l}\text { Urinary } \\
\text { problems/Incontinence }\end{array}$ & 2 & 14 & 6 & 4 & 3 & 5 \\
\hline 12 & Fatigue & 8 & 36 & 52 & 53 & 42 & 36 \\
\hline 13 & Dizziness/Vertigo & 6 & 17 & 30 & 28 & 22 & 18 \\
\hline
\end{tabular}

As depicted in Table 2, the minimum score of P-MHI before, during pregnancy, and one week, two, four, and six months after childbirth were found to be 54, 31, 15, 23, 38 and 23 (out of 100), respectively.

The median of the index before pregnancy was found to be 100, while it reached 85 and 77 during pregnancy, and within one week after childbirth, respectively. This means that at least half of the population had no health problems before pregnancy, but during pregnancy half of the women got at most 85 , and within one week after childbirth half of the women got at most 77 out of 100 . A decreasing trend of scores is visible. The median of the index reached 85, 92 and 92, within two months, four months, and six months after delivery, respectively. Even though the median of the index from the second month after childbirth started to increase, at the sixth month after delivery it remained lower than before pregnancy $(92$ vs. 100) $(\mathrm{P}<0.05)$.

Table 2. Minimum, Maximum, Quartile1, Median and Quartile3 of P-MHI at six different points in time

\begin{tabular}{lllllll}
\hline Physical maternal health index & Min & Max & Quartile1 & Median & Quartile3 \\
\hline Before Pregnancy & & 54 & 100 & 92 & 100 & 100 \\
\hline During Pregnancy & One week & 15 & 100 & 62 & 85 & 92 \\
\hline \multirow{3}{*}{ After delivery } & Two months & 23 & 100 & 69 & 77 & 92 \\
\cline { 2 - 6 } & Four months & 38 & 100 & 77 & 95 & 92 \\
\cline { 2 - 6 } & Six months & 23 & 100 & 77 & 92 & 100 \\
\hline
\end{tabular}

Means of the index at six different points in time were compared by using the repeated measures analysis of variance method. As Figure 1 shows, the mean of the index was at the lowest level one week after childbirth (76 out of 100). The next lowest mean was 2 months after childbirth (82 out of 100) $(\mathrm{P}<0.0005)$. 


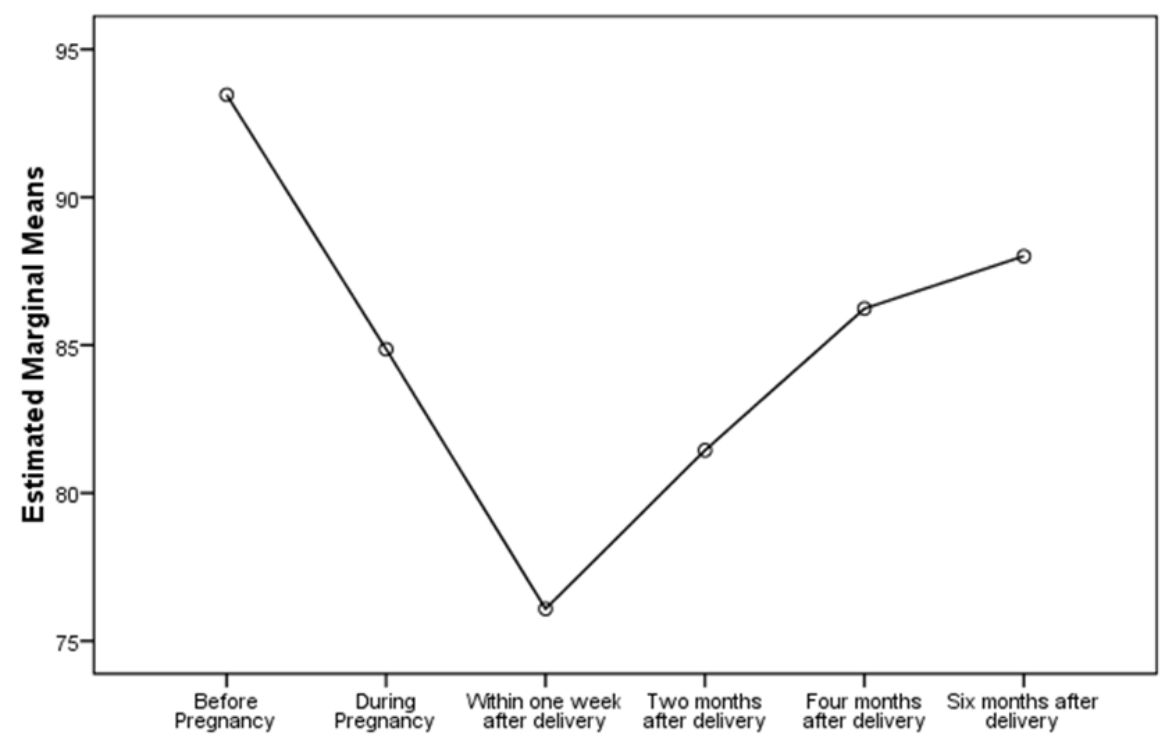

Figure 1. Means of the P-MHI at six different points in time

Comparison of the means of the index with respect to the mode of delivery, i.e., Natural Vaginal Delivery ( NVD) and Cesarean section (CS) did not show any significant differences. Implying that P-MHI in both groups declined equally.

\subsection{Participants' Flow}

According to the current scheme of children's health care in Iran, WHO proposed a regular vaccination program to be compulsory for two-, four- and six-month-old babies, and free of charge all across the country. These services are provided by Health Care Centers. Since participants in this study were from among mothers who had sought child health care services from health centers in Tehran, therefore, all the mothers were reachable during the study.

\section{Discussion}

According to P-MHI at varying time periods, mothers lose their health considerably after childbirth. Most mothers do not regain their pre-pregnancy health status even six months after childbirth. Although through cross sectional surveys, Zafar et al., (2015), found that morbidity in Pakistan and Malawi was lower in the postpartum period than the pregnancy period. The differences between their survey and the present study could be due to the different methodology (Zafar et al., 2015).

Post-natal mothers experience various problems, with back pain being the most common. The rate of this problem reported in this study is higher than the rate reported by Olsson 2012, that stated $41 \%$ of women had back pain during pregnancy. Mens 2012 reported 60.4\%, which is higher than our findings. Post-partum fatigue was found to be prevalent and was still remarkably high, i.e., $36 \%$ at the sixth month after delivery.

The mean \pm SD age of mothers was $28 \pm 5$ indicating that the mothers were in the healthiest time of their lives.

Analyzing maternal health by considering a single factor can be unreliable, especially when it has been seen that according to the mode of delivery, i.e., NVD or CS, types of complaints may change. We found that P-MHI in both methods of delivery (vaginal and cesarean section) declined equally. This means that most mothers generally suffer from some kind of post-natal problems irrespective of the mode of delivery.

Some studies were intended to assess the quality of life, including the physical component, psychological aspects and post-partum health of mothers. But most of them were cross-sectional studies, not longitudinal. Moreover, the items studied in indices, such as the Mother-Generated Index for estimating quality of life, are some general items relating to health rather than medical complications, which are considered in this paper. In most of the studies researchers focused on a mother's specific complaint (Hantoushzadeh, Javadian, Shariat, Salmanian, Ghazizadeh, \& Aghssa, 2011; Hilde, Stær-Jensen, Siafarikas, Ellström Engh, Hoff Brækken, \& Bø, 2013).

It is important to note that even before pregnancy some mothers had reported headache, back pain, constipation and other problems, and the rates of morbidities during and after pregnancy are not attributable to pregnancy alone. Therefore, in order to reduce morbidities, medical consultation and treatments should commence before pregnancy, 
assuming the pregnancy has been planned.

According to our findings, it is suggested that post-partum mothers be monitored and seriously taken care of for at least two months after being discharged from the hospital.

In addition to post-partum health services, mothers have to be motivated by health care providers availing themselves of these benefits.

It will also improve the women's lifetime health and decrease the ill-health expenses for the family and the community as well. As stated by Stenberg and colleagues (2014), investments in Reproductive, Maternal, Newborn and Child Health (RMNCH) could yield up to nine times their value in economic and social benefits.

The novelty of our findings is in identifying the P-MHI and its trend in the course of time, which indicates "when mothers need more care".

\subsection{Limitations of the Study}

Since the mothers completed the questionnaires belong to before pregnancy, during pregnancy, and one week after delivery, at the second months after delivery, it is possible that they may have forgotten some health-related issues that occurred earlier. It is assumed that generally mothers do not forget their problems within a short time.

Here we used a simple Yes or No format. Using a five or seven-point Likert scale to measure the severity of the health issue would have yielded a more accurate P-MHI index.

\subsection{Suggestions for Future Studies}

P-MHI introduced as a clinical tool to monitor maternal health. To identify those mothers that would require additional monitoring post-partum, it is suggested to work for finding an appropriate cut-off point of P-MHI. Future studies can focus on introducing and estimating the psychological health index of mothers before, during and after pregnancy.

\section{Acknowledgements}

This work has been undertaken by Grant No. 172-85/12/20 Deputy of Research, Shahid Beheshti University of Medical Sciences, Tehran, Islamic Republic of Iran.

\section{Competing Interests Statement}

The authors declare that there is no conflict of interests regarding the publication of this paper.

\section{References}

Ashford, L. (2002). Hidden suffering: disabilities from pregnancy and childbirth in less developed countries Population Reference Bureau. Retrieved from http://www.prb.org/pdf/hiddensufferingeng.pdf.

Callaghan, W. M., Creanga, A. A., \& Kuklina, E. V. (2012). Severe maternal morbidity among delivery and postpartum hospitalizations in the United States. Obstet Gynecol, 120(5), 1029-36. http://dx.doi.org/10.1097/AOG.0b013e31826d60c5

Catalin, S. B., \& Irina, A. B. (2006). Advantages of vaginal delivery. Clinical Obstetrics and Gynecology, 49(1), 167-183.

Firoz, T., Chou, D., Dadelszen, P. V., Agrawal, P., Vanderkruik, R., ... Say, L. (2013). Measuring maternal health: focus on maternal morbidity. Bulletin of the World health Organization, 91, 794-796. http://dx.doi.org/10.2471/BLT.13.117564

Glazener, C. M., Abdolla, M., Stroud, P., Naji, S., Templeton, A., \& Russell, I. T. (1995). Postnatal maternal morbidity: Extent, causes, prevention and treatment. $\mathrm{Br} J$ Obstet Gynaecol, 102(4), 282-7. http://dx.doi.org/10.1111/j.1471-0528.1995.tb09132.x

Goldszmidt, E., Kern, R., Chaput, A., \& Macarthur, A. (2005). The incidence and etiology of postpartum headaches: a prospective cohort study. Can J Anaesth, 52(9), 971-7. http://dx.doi.org/10.1007/BF03022061

Hantoushzadeh, S., Javadian, P., Shariat, M., Salmanian, B., Ghazizadeh, S., \& Aghssa, M. (2011). Stress urinary incontinence: pre-pregnancy history and effects of mode of delivery on its postpartum persistency. International Urogynecology Journal, 22(6), 651-655. http://dx.doi.org/10.1007/s00192-010-1335-6

Hilde, G., Stær-Jensen, J., Siafarikas, F., Ellström Engh, M., Hoff Brækken, I., \& Bø, K. (2013). Impact of childbirth and mode of delivery on vaginal resting pressure and on pelvic floor muscle strength and endurance. Am J Obstet Gynecol, 208(1), 50.e1-7. http://dx.doi.org/10.1016/j.ajog.2012.10.878 
Jayaratnam, S., De Costa, C., \& Howat, P. (2011). Developing an assessment tool for maternal morbidity 'near-miss'- a prospective study in a large Australian regional hospital. Aust N Z J Obstet Gynaecol, 51(5), 421-5. http://dx.doi.org/10.1111/j.1479-828X.2011.01330.x

Jones, G. L., Morrell, C. J., Cooke, J. M., Speier, D., Anumba, D., \& Stewart-Brown, S. (2011). The development of two postnatal health instruments: one for mothers (M-PHI) and one for fathers (F-PHI) to measure health during the first year of parenting. Qual Life Res., 20(7), 1011-22. http://dx.doi.org/10.1007/s11136-010-9832-0

Klein, A. M., \& Loder E. (2010). Postpartum headache. Int J Obstet Anesth, 19(4), 422-30. http://dx.doi.org/10.1016/j.ijoa.2010.07.009

Lacasse, A., \& Berard, A. (2008). Validation of the nausea and vomiting of pregnancy specific health related quality of life questionnaire. Health and Quality of Life Outcomes, 6, 32. http://dx.doi.org/10.1186/1477-7525-6-32

Mens, J. M., Huis In 't Veld, Y. H., \& Pool-Goudzwaard, A. (2012). Severity of signs and symptoms in lumbopelvic pain during pregnancy. Man Ther, 17(2), 175-9. http://dx.doi.org/10.1016/j.math.2011.12.012

Nastis, S. A., \& Crocker, T. D. (2012). Valuing mother and child health: The intrauterine environment. Econ Hum Biol., 10(3), 318-28. http://dx.doi.org/10.1016/j.ehb.2011.03.003

Olsson, C. B., Nilsson-Wikmar, L., \& Grooten, W. J. (2012). Determinants for lumbopelvic pain 6 months postpartum. Disabil Rehabil, 34(5), 416-22. http://dx.doi.org/10.3109/09638288.2011.607212

Reichenheim, M. E., Zylbersztajn, F., Moraes, C. L., \& Lobato, G. (2009). Severe acute obstetric morbidity (near-miss): a review of the relative use of its diagnostic indicators. Arch Gynecol Obstet, 280, 337-43. http://dx.doi.org/10.1007/s00404-008-0891-1

Symon, A. (2003). A review of mothers'prenatal and postnatal quality of life. Health and Quality of Life Outcomes 1, 38. http://dx.doi.org/10.1186/1477-7525-1-38

Stenberg, K., Axelson, H., Sheehan, P., Anderson, I., Gülmezoglu, A. M., Temmerman, M, et al. (2014). Study Group for the Global Investment Framework for Women's and Children's Health. Advancing social and economic development by investing in women's and children's health: A new Global Investment Framework. Lancet, 12, 383(9925), 1333-54. http://dx.doi.org/10.1016/S0140-6736(13)62231-X

Symon, A., MacDonald, A., \& Ruta, D. (2002). Postnatal Quality of life assessment: Introducing the

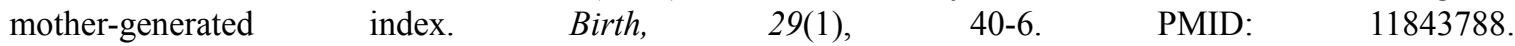
http://dx.doi.org/10.1046/j.1523-536X.2002.00154.x

Symon, A., MacKay, A., \& Ruta, D. (2003). Postnatal quality of life: A pilot study using the Mother-Generated Index. Jurnal of Advanced Nursing, 42(1), 21-29. http://dx.doi.org/10.1046/j.1365-2648.2003.02575.x

Vermani, E., Mittal, R., \& Weeks, A. (2010). Pelvic girdle pain and low back pain in pregnancy: A review. Pain Pract, 10(1), 60-71. http://dx.doi.org/10.1111/j.1533-2500.2009.00327.x

World Health Organization. (2013). Retrieved http://apps.who.int/iris/bitstream/10665/112682/2/9789241507226_eng.pdf?ua=1.

World Health Organization. (2014). Retrieved from http://who.int/reproductive health/topics/mdgs/en/

Zafar, S., Jean-Baptiste, R., Rahman, A., Neilson, J. P., \& Van den Broek, N. R. (2015). Non-life Threatening Maternal Morbidity: Cross sectional Surveyes from Malawi and Pakistan. PLoS One, 10(9), e0138026. http://dx.doi.org/10.1371/journal.pone.0138026

\section{Copyrights}

Copyright for this article is retained by the author(s), with first publication rights granted to the journal.

This is an open-access article distributed under the terms and conditions of the Creative Commons Attribution license (http://creativecommons.org/licenses/by/4.0/). 